\title{
Autosomal recessive late onset multisystem disorder with cerebellar cortical atrophy at necropsy: report of a family
}

\author{
AE HARDING, JV DIENGDOH, AJ LEES \\ From the National Hospitals for Nervous Diseases, Queen Square and Maida Vale, London, UK
}

SUMMARY A sister and brother developed a progressive syndrome comprising bulbar palsy, supranuclear ophthalmoplegia, facial impassivity, and cerebellar ataxia together with a mixed pyramidal and extrapyramidal deficit in the limbs, in the fourth decade of life. Their parents were unaffected and inheritance was probably autosomal recessive. The female patient, who presented initially with bulbar and extrapyramidal dysfunction, was found to have cerebellar cortical atrophy at necropsy. The basal ganglia and brainstem were normal.

The combination of progressive cerebellar, extrapyramidal and pyramidal dysfunction developing in adult life is rare. The aetiology of these "multiple system disorders" is obscure and most patients do not have similarly affected relatives. The occurrence of this clinical syndrome as an autosomal recessive trait has not been well documented, although extrapyramidal and pyramidal signs are common in cases of autosomal dominant late onset cerebellar ataxia. ${ }^{\prime}$ In previous reports of families where only members of one sibship were affected, usually little or no information was given about the patients' parents or they died before the age at which they would be expected to develop symptoms if inheritance was dominant. ${ }^{2-5}$

In this paper we describe autosomal recessive inheritance of a mixed cerebellar, extrapyramidal and pyramidal syndrome. Cerebellar cortical atrophy was found at necropsy in the index case. The pedigree of the family is shown in fig 1 .

\section{Case reports}

III.1 This female first noticed progressive slurring of speech at the age of 37 years in 1969. Three years later she developed dysphagia for solid food and nasal regurgitation of fluids. On examination in 1973 she had a slurring bulbar dysarthria but normal palatal and tongue movements. The

Address for reprint requests: Dr AE Harding, The National Hospital for Nervous Diseases, Queen Square, London, WC1 3BG, UK

Received 8 December 1983 and in revised form 15 February 1984. Accepted 18 February 1984 jaw jerk was brisk. There was a paucity of lower facial movements. No abnormalities were detected in the limbs. Investigations including electroencephalogram, cerebrospinal fluid examination, extensive electromyographic (EMG) muscle sampling and nerve conduction studies were normal. No firm diagnosis was made.

In 1975 she had a subarachnoid haemorrhage from a right posterior communicating artery aneurysm which was treated conservatively and did not result in any persistent neurological disability. Two years later she was admitted to the Whittington Hospital (Dr PB Croft) for reassessment. She was slightly emotionally labile and anarthric. There was mild lid retraction but eye movements were full. All

II

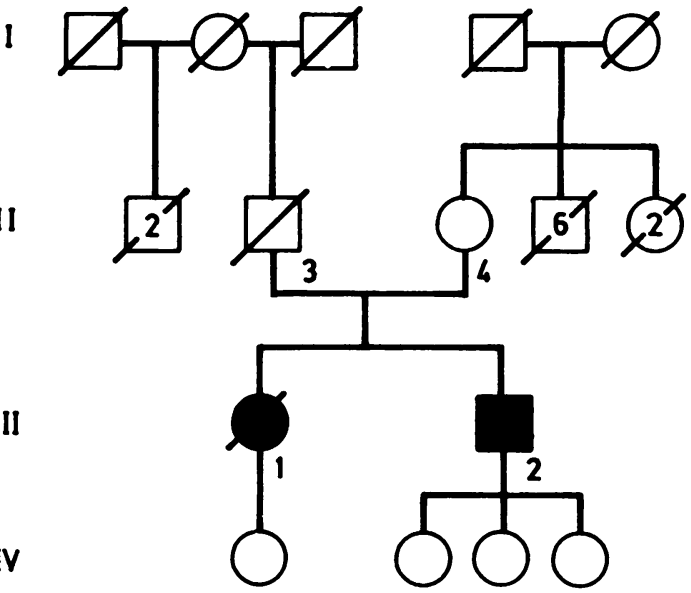

Fig 1 Pedigree of family (square = male, circle $=$ female, filled symbol = affected, open symbol = unaffected, oblique line $=$ deceased). 
palatal movements were reduced. The tongue was wasted and moved slowly. Occasional athetoid movements were observed in the limbs, together with moderate cerebellar ataxia. Her handwriting was very small. She was unable to release grip quickly and this was thought to be due to myotonia. Her gait was broad based and ataxic. Serum copper and caeruloplasmin and plasma creatine kinase were normal. EMG of a number of muscles in the left arm was normal. A triceps muscle biopsy showed slight variation in fibre size and patchy increase of endomysial connective tissue.

Over the next three years the patient's dysphagia progressed and she lost weight. She became unable to write, had difficulty in straightening her fingers, and developed generalised weakness of the arms. She was unable to walk more than three or four steps because of poor balance and stiffness of the legs. She had occasional urge incontinence.

On examination in 1980 , in addition to the findings noted in 1977 , there was no voluntary palatal movement but the gag reflex was present. Muscle tone was reduced in the arms and there was wasting of the shoulder girdle and small hand muscles bilaterally with generalised weakness. She still appeared to have myotonia of grip but there was no percussion myotonia. Muscle weakness was evident more proximally than distally in the legs, and there was marked cerebellar ataxia in all four limbs. The tendon reflexes were brisk and the plantar responses flexor. Proprioception was reduced at the toes and vibration sense lost below the knees. A CT scan showed cerebellar atrophy.

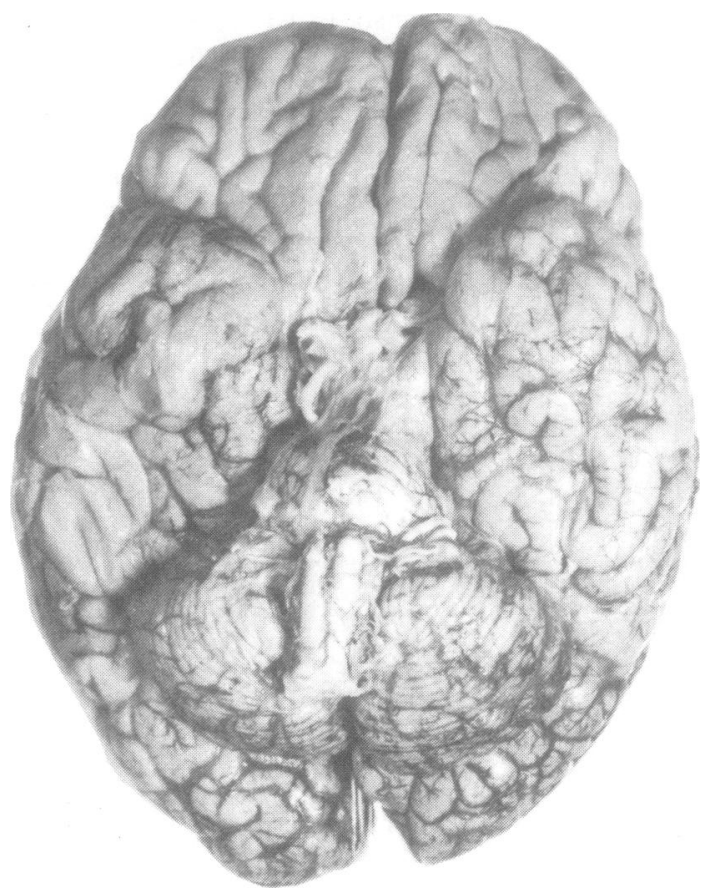

Fig 2 Brain of case III.1, showing markedly atrophic cerebellum and normal cerebral hemispheres.

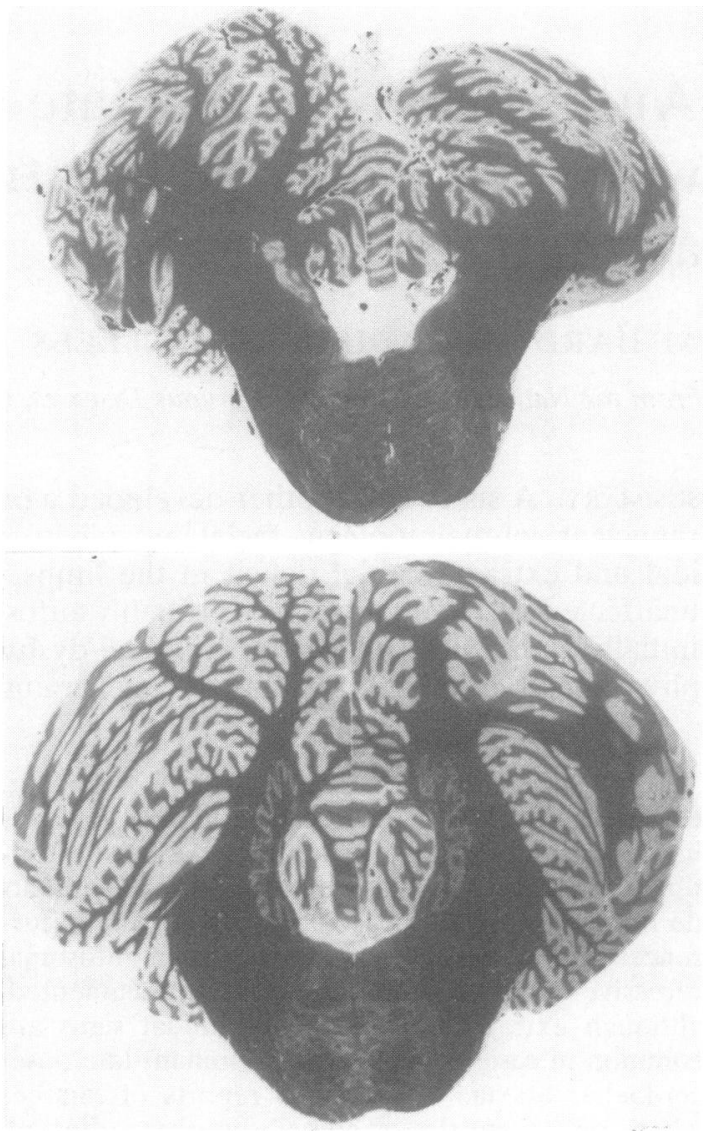

Fig 3 Cerebellar atrophy in case III.1 (above). There is slight shrinkage of the middle cerebellar peduncles but the pons is of normal size. The section shown below is taken from a control brain of the same age and sex. (Heidenhain's myelin stain)

The patient's condition deteriorated generally over the next two years and she died in 1982 .

At necropsy the brain weighed $1286 \mathrm{~g}$. The cerebellar hemispheres were markedly atrophic compared to the cerebral hemispheres which were of normal size and appearance (fig 2). Transverse sections of the cerebellum taken at the mid-pons level and embedded in celloidin confirmed the presence of cerebellar atrophy compared to a normal control (fig 3). Although the middle cerebellar peduncles were slightly shrunken the pons was of normal size and appearance.

Microscopic examination showed an almost complete loss of Purkinje cells with only occasional degenerative neurons remaining. There was relatively little reduction in the number of granule cells. The molecular layer of the cerebellar cortex showed proliferation of Bergmann's glia (fig 4). Silver impregnation demonstrated the presence of "empty baskets" formed by the arborisations of axon ter- 


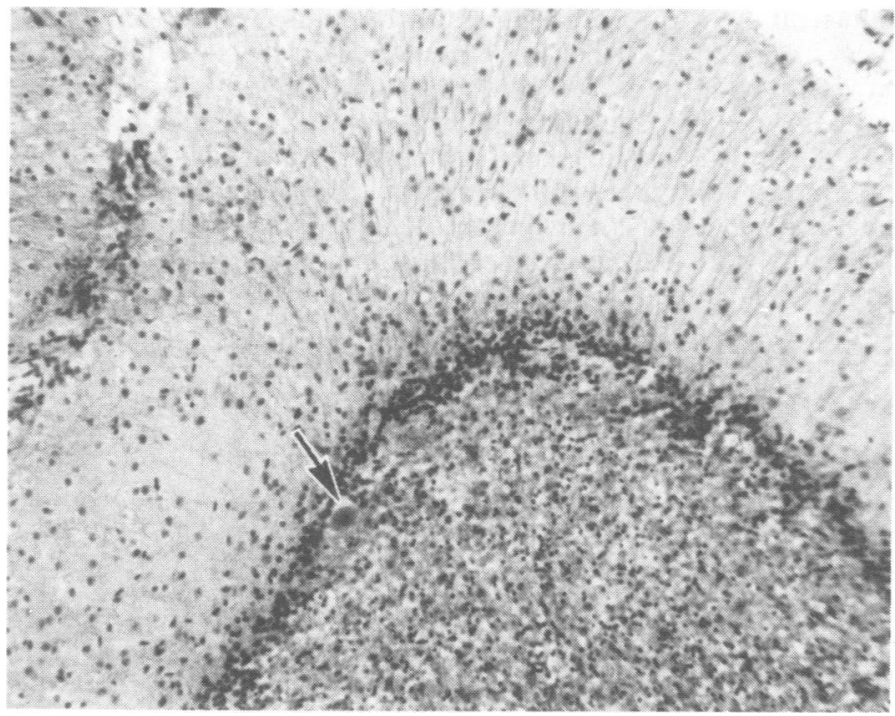

Fig 4 Cerebellum of case III.1, showing marked loss of Purkinje cells with only an occasional remaining neuron (arrow). There is relative preservation of the granule cells, and proliferation of Bergmann's glia in the molecular layer. (Phototungstic acid haematoxylin stain $\times 150$ )

minals of the stellate cells in the molecular layer around the absent Purkinje cells. There were fusiform swellings ("torpedoes") on the axons of the degenerated Purkinje cells. The cerebellar foliae were small and the degeneration of the cortex affected all parts of it equally. Both dentate nuclei were atrophic with associated neuronal loss and marked gliosis. The inferior olives were not atrophic and contained the normal complement of neurons. The neurons of the basal ganglia, substantia nigra and cerebral cortex were normal in appearance and number. Sections of the spinal cord taken at various levels were of normal histological appearance.

III.2 This 46-year-old dentist first noticed slurring of speech when he was tired at the age of 37 years. Two years later he developed mild unsteadiness of gait and a tendency to fall backwards. His handwriting had become smaller and less legible. On examination in 1976 he had a staring expression and a mild cerebellar dysarthria. Tone and power in the limbs were normal. There was slight impairment of coordination in the legs but his gait was normal. The tendon reflexes were brisk and the plantar responses flexor. Routine investigations and extensive studies of copper metabolism were normal. A CT scan showed prominence of the fourth ventricle.

Over the next seven years the patient's symptoms of unsteadiness progressed, and he developed a tendency to trip. In 1980 he noticed diplopia which was present mainly on reading. His hands became clumsy but he was still able to work. For one year he had had urgency of micturition and occasional urge incontinence. He tended to choke when drinking liquids. He denied any intellectual deterioration but admitted to increased irritability. A CT scan performed in 1980 showed prominent cerebellar atrophy.

On examination in 1983, short term memory was impaired. He was severely dysarthric and exhibited micrographia. There was lid retraction, infrequent blinking or lower facial movement, and a positive glabellar tap. The jaw jerk was increased. Tongue movements were slow and voluntary palatal movement was reduced although the gag reflex was brisk. Eye movement examination, including electro-oculography (Dr NGR Page), showed poor convergence and bilateral limitation of abduction. Upgaze was $50 \%$ of normal on command, improved on pursuit, and normal on performing the doll's head manoeuvre. Downgaze was normal. Vertical saccades were slow. Horizontal saccades were mildly hypometric and saccadic velocities on abduction were just below the normal range. Tone was slightly increased in the limbs and fine finger movements were impaired. There was mild heel-shin ataxia but coordination was otherwise normal. The tendon reflexes were all increased and the abdominal reflexes absent. The plantar responses were flexor and sensation was normal. The patient was unable to walk heel to toe and tended to fall backwards. Electromyographic sampling in the right arm and leg was normal and showed no evidence of myotonia. Motor and sensory nerve conduction studies were normal. Leucocyte glutamate dehydrogenase activity was in the normal range.

The patients' father (II.3) died at the age of 68 years and their mother (II.4) was alive and well aged 74. Neither had any neurological symptoms, and they were not consanguineous. There was no history of neurological disease in any other members of the family, and the children of III.1 and 2 , aged 14 to 24 years, were stated to be normal.

\section{Discussion}

The clinical features of the inherited disorder seen in these two sibs were somewhat variable. The index case presented initially with symptoms and signs of a bulbar palsy and later developed prominent cerebellar and extrapyramidal dysfunction. Her brother had more marked extrapyramidal signs, which were pre- 
sent early in his illness, together with a supranuclear disorder of eye movements, pseudobulbar palsy and pyramidal signs in the limbs. His cerebellar deficit was slight, despite the presence of definite cerebellar atrophy on computed tomography. These two patients were clinically very similar to some of those recently described with glutamate dehydrogenase deficiency, ${ }^{6}$ but the activity of this enzyme was normal in case III.2. As is frequent in the hereditary ataxias, there was little clinico-pathological correlation in the index case. There was cerebellar cortical atrophy but the brainstem and basal ganglia were normal, despite her prominent bulbar palsy.

The majority of cases of dominantly inherited cerebellar ataxia are found to have the pathological syndrome of olivopontocerebellar atrophy at necropsy, often with additional degenerative changes in the basal ganglia and spinal cord. ${ }^{1}$ Pure cerebelloolivary atrophy has been observed in cases of autosomal recessive cerebellar ataxia associated with hypogonadism, ${ }^{7}$ and a later onset dominantly inherited pure cerebellar syndrome. ${ }^{8}$ Staal and colleagues ${ }^{9}$ have recently described a disorder comprising spastic paraplegia, optic atrophy, supranuclear ophthalmoplegia, dementia and pseudobulbar palsy in five sibs. Only one had cerebellar ataxia. Onset was in the third to sixth decades of life and inheritance appeared to be autosomal recessive. Necropsy of one patient (who was not ataxic) showed cerebello-olivary atrophy gliosis of the dentate nuclei, and loss of myelin in the spinocerebellar tracts and posterior columns in the spinal cord.

Pure cerebellar cortical atrophy is rare and its distinction from cerebello-olivary atrophy has been disputed, as olivary atrophy is known to occur as a secondary phenomenon when there is cerebellar cortical atrophy. ${ }^{7}$ Degeneration of the inferior olivary nuclei was present in a number of cases previously described as examples of cerebellar cortical atrophy. ${ }^{10}$ Perhaps the only convincing report of familial pure cerebellar cortical atrophy is that of Richter, ${ }^{3}$ who described progressive cerebellar ataxia developing in the fifth to sixth decades in three out of five sibs. A variable degree of dementia was present in two. The patients' parents both died young so it is impossible to state the mode of inheritance with certainty. A necropsy was performed on one patient and the findings were very similar to those described here, showing marked cerebellar cortical atrophy and loss of cells in the dentate nuclei but preservation of the brainstem nuclei.
Autosomal recessive inheritance of degenerative cerebellar disorders is clearly rare. Nevertheless, its existence, as demonstrated by the family described here, should be recognised. The aetiology of similar "sporadic" cases is at present unknown; it is likely that some of them are caused by autosomal recessive genes as single cases of any recessive disorder will be at least five times as common as familial ones in populations where mean family size is small. ${ }^{11}$

We thank Dr W Michael for permission to study case III.2, and Dr D Aubby for performing the leucocyte glutamate dehydrogenase assay.

\section{References}

' Harding AE. The clinical features and classification of the late onset autosomal dominant cerebellar ataxias: a study of eleven families, including descendants of the "Drew family of Walworth". Brain 1982;105:128.

${ }^{2}$ Aring CD. Degeneration of the basal ganglia associated with olivopontocerebellar atrophy. J Nerv Ment Dis 1940;92:448-70.

${ }^{3}$ Richter RB. A clinicopathological study of parenchymatous cortical cerebellar atrophy: report of familial case. J Nerv Ment Dis 1940;91:37-46.

${ }^{4}$ Sigwald J, Lapresle J, Raverdy P, de Recondo J. Atrophie cérébelleuse familiale avec association de lésions nigériennes et spinales. Presse Méd 1964;72:557-68.

${ }^{5}$ Brion S, de Recondo J. Ophtalmoplegie nucléaire progressive et hérédo-dégénérescence spino-cérébelleuse. Rev Neurol (Paris) 1967;116:383-400.

- Duvoisin RC, Chokroverty S, Lepore F, Nicklas W. Glutamate dehydrogenase deficiency in patients with olivopontocerebellar atrophy. Neurology (NY) 1983;33:1322-6.

${ }^{7}$ Holmes G. A form of familial degeneration of the cerebellum. Brain 1907;30:466-89.

${ }^{8}$ Hoffman PM, Stuart WH, Earle KM, Brody JA. Hereditary late onset cerebellar degeneration. Neurology (Minneap) 1971;21:771-7.

9 Staal A, Stefanko SZ, Jennekens FGI, Penning de Vries-Bos LH, van Gijn J. Autosomal recessive spino-olivocerebellar degeneration without ataxia. $J$ Neurol Neurosurg Psychiatry 1983;46:648-52.

${ }^{10}$ Hall B, Noad KB, Latham O. Familial cortical cerebellar atrophy. Brain 1941;64:178-94.

"Harding AE. The Hereditary Ataxias and Related Disorders. Edinburgh: Churchill Livingston, 1984 (in press). 